\title{
DESIGN UNIVERSAL APLICADO A MATERIAL DIDÁTICO PARA CRIANÇAS COM DEFICIÊNCIA VISUAL: UMA EXPERIÊNCIA DIDÁTICA
}

Jamille Noretza de Lima Lanutti

PPG Design - Unesp Bauru

jamille_lanutti@hotmail.com

Luis Carlos Paschoarelli

PPG Design - Unesp Bauru

Icpascho@gmail.com

Resumo: O design universal preconiza que produtos e sistemas possam ser acessíveis por um amplo e diversificado grupo de usuários. A aplicação de seus princípios, no design gráfico de material didático, pode contribuir para a integração de crianças com deficiência visual no processo de educação infantil. Este estudo apresenta uma atividade didática em um curso de ensino superior em design, cujos estudantes desenvolveram diferentes alternativas (protótipos), as quais foram avaliados por um grupo de especialistas. Os resultados desta avaliação apontam que a aplicação dos princípios do Design Universal em projetos de design gráfico criam uma experiência de integração social de expressiva importância para estudantes de design.

Palavras-chave: Design Universal, didática, deficiência visual

Abstract: Universal design calls for products and systems can be accessed by a broad and diverse group of users. The application of its principles in graphic design courseware, can contribute to the integration of visually impaired children in early childhood education process. This study presents a didactic activity in a higher education course in design, whose students have developed different alternatives (prototypes), which were evaluated by a group of experts. The results of this assessment indicate that the application of Universal Design principles in graphic design projects create a social integration experience of expressive importance for design students.

Keywords: Universal design, didactic, visual impairment 


\section{INTRODUÇÃO}

Segundo o Instituto Brasileiro de Geografia e Estatística (IBGE, 2010) 45,6 milhões de pessoas tem algum tipo de deficiência, o que corresponde a $23,91 \%$ da população brasileira.

Pessoas com deficiência geralmente enfrentam dificuldades em suas atividades da vida diária (AVDs), inclusive ao ingressarem nas escolas, seja por dificuldades de natureza física, sensorial, cognitiva, ou ainda por algum fator social, como o preconceito (SOARES et al., 2012).

Segundo Gasparetto (2009) um dos mecanismos necessários para a remoção das barreiras existentes na vida da pessoa com deficiência é a utilização de recursos de Tecnologia Assistiva (TA). Radabaugh (2001) afirma que as TAs facilitam a vida das pessoas sem deficiência, no entanto, para as pessoas com deficiência, ela torna as coisas possíveis. Além disso, para Santos (2014), a escola tem um papel fundamental na inclusão de pessoas com necessidades especiais, pois deve ter "o comprometimento de promover e dispor tecnologias de apoio personalizadas às necessidades individuais de cada criança e/ou jovem com deficiências" (p. 10). Assim, com o apoio das novas tecnologias, estas crianças e jovens poderão ter acesso às oportunidades educativas semelhantes a dos demais colegas de escola, desenvolvendo autonomia e novas capacidades.

Este trabalho tem o objetivo de compreender e avaliar a adequação da aplicação dos princípios do Design Universal por estudantes de Design em um projeto de tecnologia assistiva voltado para inclusão do Deficiente Visual; e verificar (por meio de análise de especialistas) como os resultados podem contribuir no esclarecimento da questão, entre estudantes de design.

\section{REVISÃO TEÓRICA}

\subsection{Educação Inclusiva e tecnologia assistiva}

Nota-se na atualidade um esforço coletivo para inclusão social da pessoa com deficiência. No entanto, de nada valem os estímulos à inclusão destas pessoas ao mercado de trabalho, se estas não estiverem previamente integradas a sociedade. Um meio de inclusão social importante esta no ambiente da escola, tanto para o deficiente, quanto para diminuir o estigma negativo atribuído à ele.

Durante muito tempo estimulou-se um sistema de educação exclusivo para pessoas com necessidades especiais, chamado de Educação Especial. No entanto, leis e o próprio Estatuto da Criança e do Adolescente (1990), afirmam como obrigação dos pais ou responsável "matricular seus filhos na rede regular de ensino", afirmando ainda que "nenhuma criança ou adolescente será objeto de qualquer forma de negligência, discriminação, exploração, violência, crueldade e opressão, punido na forma da lei qualquer atentado, por ação ou omissão, aos seus direitos fundamentais".

Contudo, o acesso à educação, para pessoas com deficiência vem ocorrendo de maneira lenta, mesmo com a Lei de Diretrizes Básicas para a Educação, que garante a inserção da criança com deficiência em escolas ditas regulares (MENDES, 2006).

Segundo o censo de 2010 (INEP, 2010), foram matriculados 702.603 alunos na educação especial, com um aumento de $10 \%$ em comparação a 2009 . O que não necessariamente evidencia o êxito da política de inclusão na educação básica. Pois, 
mais do que o número de crianças matriculadas, é necessário quantificar a permanência dessas crianças nas escolas, o que de fato consiste um grande desafio.

De acordo com Mendes (2006, p.15), as mazelas da educação especial brasileira não se limitam à falta de acesso, pois isto não garante uma educação de qualidade. Uma educação especial de qualidade estaria ainda associada a qualificação profissional de todos os envolvidos no processo e na existência de recursos apropriados. Afinal, a educação inclusiva requer que os educadores estejam, permanentemente informados sobre os processos educacionais e necessidades especiais das pessoas com deficiência e das possibilidades de TAs.

TAs devem ser constantemente aprimoradas, proporcionando, à pessoa com deficiência maior independência, qualidade de vida e inclusão social. Devem também proporcionar ampliação de sua comunicação, mobilidade, controle de seu ambiente, habilidades de seu aprendizado, trabalho e integração com a família, amigos e sociedade.

\section{2 Deficiência visual}

Com base na população mundial, a Organização Mundial de Saúde estima que mais de 161 milhões de pessoas sejam portadoras de deficiência visual, das quais 124 milhões teriam baixa visão e 37 milhões seriam cegas. Desse total, estima-se que o total de $90,0 \%$ concentra-se nos países em desenvolvimento e a maior parte poderia ser evitada por prevenção ou tratamentos existentes (WEST e SOMMER, 2001).

No Brasil, 18,6\% da população brasileira possui deficiência visual, sendo - entre todas as deficiências - a de maior ocorrência (IBGE, 2010). Vale lembrar que se adota como deficiência visual a presença de cegueira ou baixa visão; e que a Organização Mundial de Saúde (OMS, 1993) classifica:

[...] a baixa visão é classificada em: perda moderada da visão, situação em que o sujeito apresenta acuidade visual entre $20 / 60$ a 20/200; perda grave da visão, entre 20/200 a 20/400; perda profunda da visão, entre 20/400 a 20/1200 no melhor olho com melhor correção (OMS, 1993).

Destaca-se ainda que a baixa visão caracteriza-se por ser uma alteração significativa da capacidade funcional da visão, que interferem ou limitam o desempenho visual (BRUNO, 1997). E que, mesmo utilizando a melhor correção (óculos e lentes), os indivíduos continuam apresentando baixa visão.

De acordo com Lopes et al. (2004), cerca de $80 \%$ de tudo que o ser humano percebe chega ao cérebro através da visão, agindo como estímulos que produzem a percepção da aprendizagem e que são fundamentais no desenvolvimento de funções, tais como: locomoção e mobilidade. Tal desenvolvimento é seriamente comprometido quando se perde a visão precocemente ou no caso de já se ter nascido cego. Assim, as dificuldades enfrentadas por pessoas com deficiência visual, com relação aos potenciais efeitos negativos no processo de aprendizagem, demonstram a importância de TAs como ferramentas de apoio para minimizar esses problemas.

\subsection{Design Universal}

São muitas as definições para o termo Design Inclusivo, que muitas vezes se confundem com os da TAs e Design Universal (MAIA, 2009). No entanto esses não são mesmo conceitos tão diferentes assim.

Alvarenga (2006) defende que o Design Inclusivo se preocupa em incluir indivíduos que não são contemplados normalmente em projetos de Design, como 
pessoas de baixa renda, idosos e pessoas com deficiência. Dessa forma, este princípio se diferencia do Design Universal, por ter o objetivo de envolver o maior número possível de indivíduos, porém sabendo que atingir todos é uma tarefa difícil ao se pensar em um único produto.

O termo Design Universal, do inglês Universal Design, surgiu em 1993, e é definido pela NBR 15290 como "Forma de conceber produtos, meios de comunicação, serviços e ambientes para serem utilizados por todas as pessoas, o maior tempo possível, sem a necessidade de adaptação, beneficiando pessoas de todas as idades e capacidades" (NBR15290, 2005 apud. MAIA, 2009).

Ribeiro et al. (2001) cita os sete princípios do Design Universal definidos pelo Centro de Design Universal da Universidade Estadual da Carolina do Norte em 1998:

Uso Equitativo: O design não estigmatiza ou deixa em desvantagem nenhum grupo de usuários.

Flexibilidade no uso: O design acomoda uma variedade de preferências e habilidades individuais.

Simples, Uso Intuitivo: A utilização do design é de fácil compreensão, sem experiência prévia, conhecimento, linguagem própria, ou exigência de constante concentração por parte do usuário.

Informações Perceptíveis: $O$ design comunica efetivamente as informações necessárias ao usuário, sem a necessidade de pré-condições ambientais ou até mesmo habilidades sensoriais específicas.

Tolerância ao Erro: $O$ design minimiza riscos e consequências adversas de acidentes ou ações desatentas.

Baixo Desgaste Físico: O design pode ser utilizado de maneira eficiente e confortável, com o mínimo de fadiga.

Tamanho e Espaço para o Uso e Alcance: Tamanho apropriado e espaço são considerados para o alcance, manipulação, utilização, independente da postura, do tamanho do corpo, da mobilidade do usuário.

\section{OBJETIVO}

O presente estudo teve como objetivo compreender e avaliar a adequação dos princípios do Design Universal por estudantes de Design, em projetos desenvolvidos durante atividade didática, visando a inclusão do Deficiente Visual.

\section{DESENVOLVIMENTO}

Este estudo é parte de uma experiência didática, realizada no segundo ano do curso de Design na Universidade Sagrado Coração (USC), em Bauru. Na ocasião, os alunos munidos de conhecimentos sobre Design Universal, foram estimulados a desenvolver projeto de material didático, o qual deveria promover a inclusão do deficiente visual no processo de alfabetização.

Dessa forma, após aula apresentando os princípios do Design Universal e critérios estabelecidos pela Organização Mundial da Saúde (OMS, 2003) para deficiência visual, as atividades de projeto objetivaram o desenvolvimento da página de uma cartilha inclusiva. Cada aluno utilizou uma letra do alfabeto, tendo como "usuário" crianças com deficiência visual total e/ou parcial. 
Os alunos foram sensibilizados quanto a obrigatoriedade de a criança ser aceita em escolas regulares, e quanto a falta de estrutura e materiais didáticos voltado para crianças com deficiência visual na grande maioria das escolas.

Além disso, realizou-se experimentação na qual os alunos, observando o alfabeto em braile, foram colocados a tatear uma palavra escrita em braile. E por fim pediu-se que projetassem uma página de cartilha didática para alfabetização de crianças.

\subsection{Objetos de estudo}

Ao todo foram produzidas 60 páginas de cartilha com diferentes letras do alfabeto, entre as quais foram selecionados seis exercícios concluídos, que apresentaram soluções diferentes entre si.

A Página de cartilha A (figura 1) trabalhou uma cor única de fundo, trabalhando os elementos com dois tons diferentes do mesmo verde, obtendo assim alto contraste entre elementos e fundo. O braile, além de alto relevo, é aparente e apresentado em diferentes dimensões de maneira decrescente, assim como as letras, maiores no alto da página e diminuem gradativamente até a parte inferior da mesma.
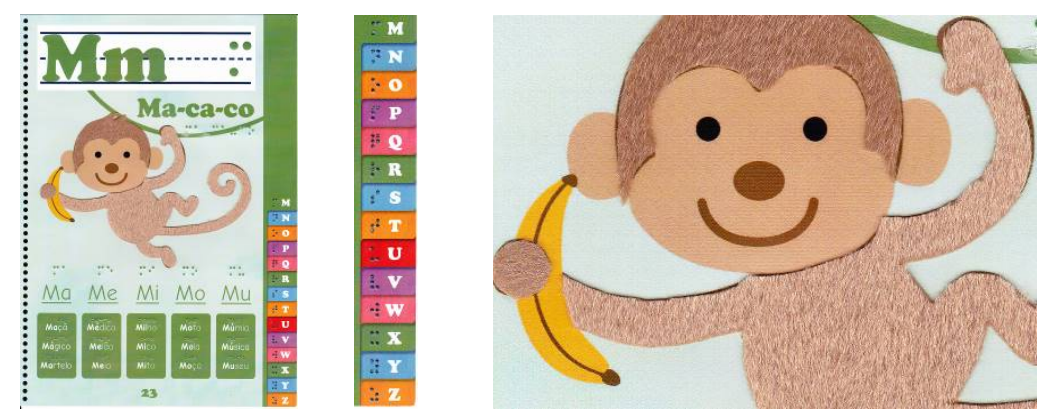

Figura 1 - (a) Página de cartilha A, (b) Guias de acesso laterais em destaque, e (c) Detalhe do relevo no elemento figurativo da página. Fonte: Elaborado pelo autor.

Como diferencial este projeto tem guias laterais com recorte e sobrepostas, que objetivam facilitar o acesso rápido a página de uma determinada letra que se queira (figura $1 b$ ). Além disso, possui alto relevo no elemento figurativo da página (o macaco) com textura obtida com colagem de tecido felpudo (figura 1c).

$\mathrm{Na}$ Página de cartilha B (figura 2) utilizou-se uma imagem no fundo, com elementos de diferentes cores. O braile, além de alto relevo, é aparente e apresentado em diferentes dimensões de maneira decrescente, assim como as letras, maiores no alto da página e diminuem gradativamente até a parte inferior da mesma.
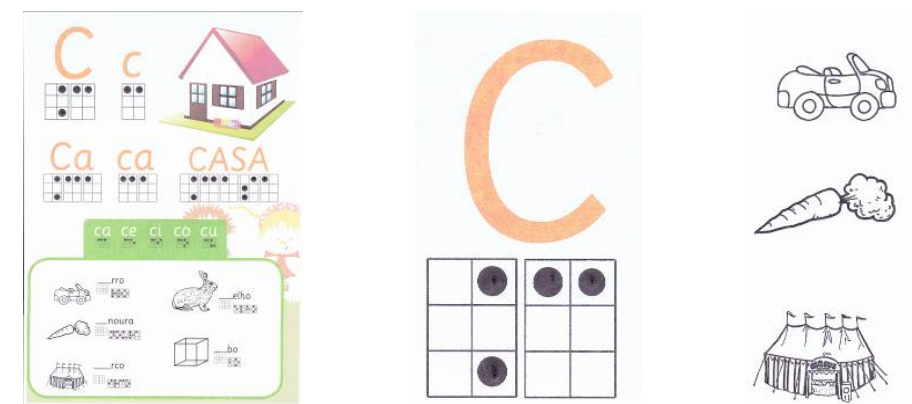

Figura 2 - (a) Página de cartilha B, (b) Detalhe das linhas e colunas aparentes, e (c) Detalhe dos variados elementos figurativos da página. Fonte: Elaborado pelo autor. 
Neste projeto deu-se maior ênfase à formação do braile, demonstrando sua estrutura por meio de linhas e colunas aparentes (figura $2 b$ ); e foram trabalhados todos os elementos figurativos com contornos em relevo (figura $2 \mathrm{c}$ ).

Já a Página de cartilha $\mathrm{C}$ (figura 3 ) teve o fundo preenchido com uma textura que lembra o elemento figurativo escolhido (a laranja) e que também tem relação com a cor escolhida em todos os elementos da página. Mas neste projeto as letras em braile, embora também aparentes, aparecem de uma única dimensão em todo o leiaute.
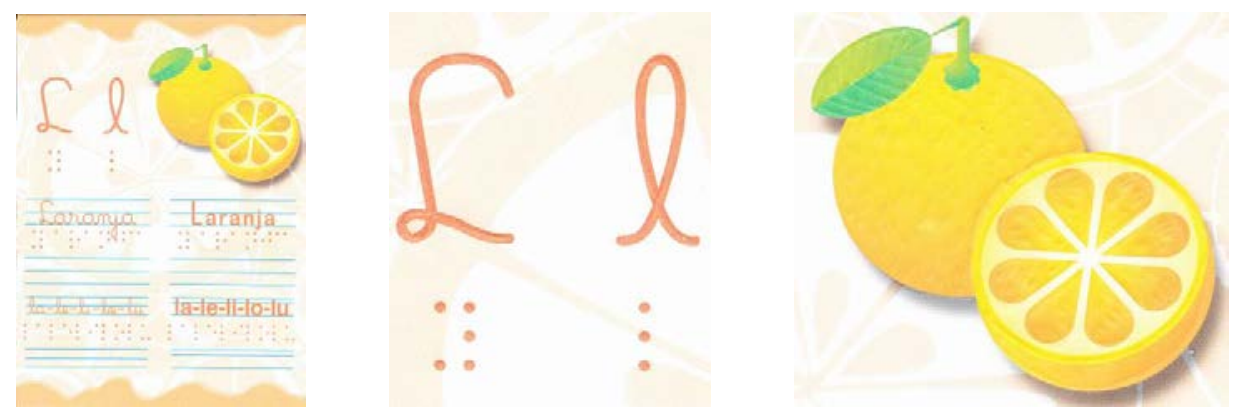

Figura 3 - (a) Página de cartilha C, (b) Detalhe das letras em alto relevo, e (c) Detalhe do relevo no elemento figurativo da página. Fonte: Elaborado pelo autor.

Como diferencial este último projeto estimula o uso do reglete á punção materiais utilizados para iniciar a escrita em braile - que deve ser apoiado na linha inferior da tarefa proposta que esta em relevo. Destaca-se que, do conjunto de linhas até as letras em braile, há um altura de quatro centímetros, medida atribuída a reglete de 4 linhas e 28 colunas. Além disso, nesta página, todas as letras possuem alto relevo (figura 3b), assim como o elemento figurativo também possui textura, apenas em relevo.

Na página de cartilha D (figura 4), utilizou-se um fundo branco com cor azul escuro, favorecendo alto contraste. Os elementos em braile não estão visíveis (figura 4b), mas - acompanhando a proporção das letras - aparecem em relevo em três diferentes dimensões.
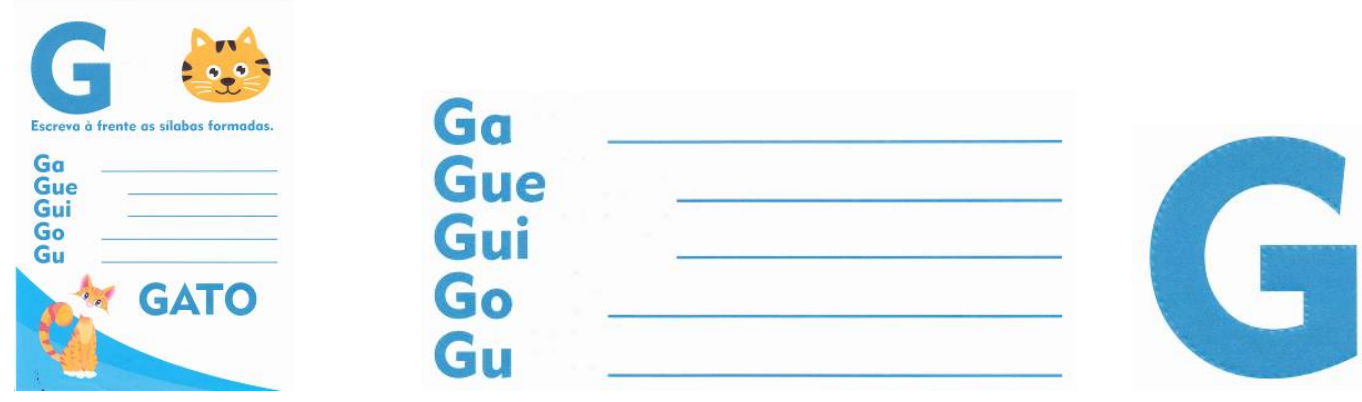

Figura 4 - (a) Página de cartilha D, (b) Detalhe da invisibilidade do braile, e (c) Detalhe do relevo pontilhado. Fonte: Elaborado pelo autor.

Quanto aos elementos figurativos, esta página oferece relevo pontilhado (figura 4b) apenas para o gato na parte superior direita da folha e para a letra $G$ maiúscula. Permitindo, assim como a página anterior, o uso do reglete á punção que pode ser apoiado nas linhas em relevo. 
A Página de cartilha E (figura 5) possui fundo branco com variadas cores e estampas laterais. O braile, além de alto relevo, é aparente e apresentado em diferentes dimensões de maneira decrescente, assim como as letras, maior no alto da página e menor na parte inferior da mesma.
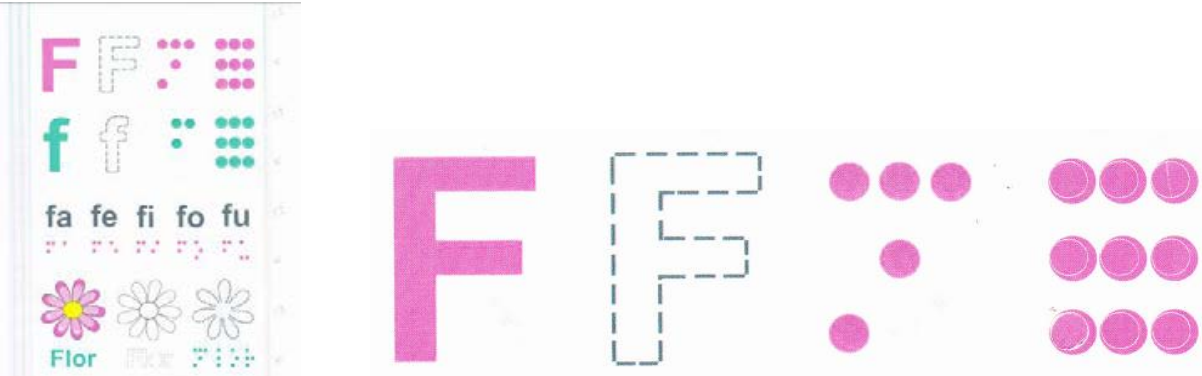

Figura 5 - (a) Página de cartilha E e, (b) Detalhe da invisibilidade do braile.

Fonte: Elaborado pelo autor.

Este projeto, como diferencial, permite que o aluno com visão pinte ou contorne a letra pontilhada, e o aluno com deficiência visual construa a letra retirando os adesivos e criando um baixo relevo ao observar por meio do tato o alto relevo ao lado (figura 5b).

E na Página de cartilha F (figura 6) utilizou-se fundo branco com elementos de variados tons de uma mesma cor. O braile é aparente e é apresentado em duas dimensões diferentes, porém bastante próximas.
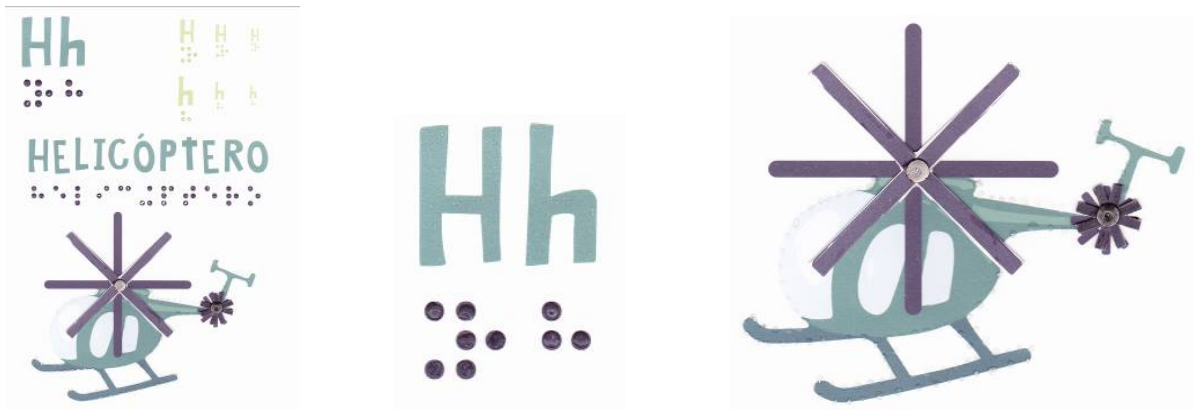

Figura 6 - (a) Página de cartilha F, (b) Detalhe do relevo do braile, e (c) Detalhe do relevo pontilhado e da hélice que gira. Fonte: Elaborado pelo autor.

Esta página não apresenta nenhuma atividade de escrita, mas permite a interação com o elemento figurativo (helicóptero), por meio das hélices que giram ao redor de um rebite. Valendo destacar que o elemento figurativo (helicóptero) todo também possui contorno.

\subsection{Procedimentos}

Para que a análise destes trabalhos não ocorresse de forma arbitrária e subjetiva, realizou-se avaliação com três profissionais especializados em diferentes áreas de atuação. Assim sendo, participaram do estudo: um designer gráfico, um fisioterapeuta, e uma terapeuta ocupacional.

Estabeleceram-se critérios de avaliação, baseados nos princípios do Design Universal (Igualitário, Intuitivo, Fácil percepção, Seguro, Sem dificuldade e Abrangente) 
e também na composição (Diagramação, Tipografia, Recursos de Relevo, Cores, Elementos Figurativos, Custo de produção e Adequação ao Público Alvo).

Os critérios estabelecidos foram organizados em um protocolo digital elaborado na plataforma Google Forms (figura 7), onde cada profissional, individualmente, pôde avaliar os trabalhos, tendo como base uma escala na qual zero é o valor mínimo e dez o valor máximo.

PESQUISA DE MATERIAL DIDÁTICO

INCLUSIVO

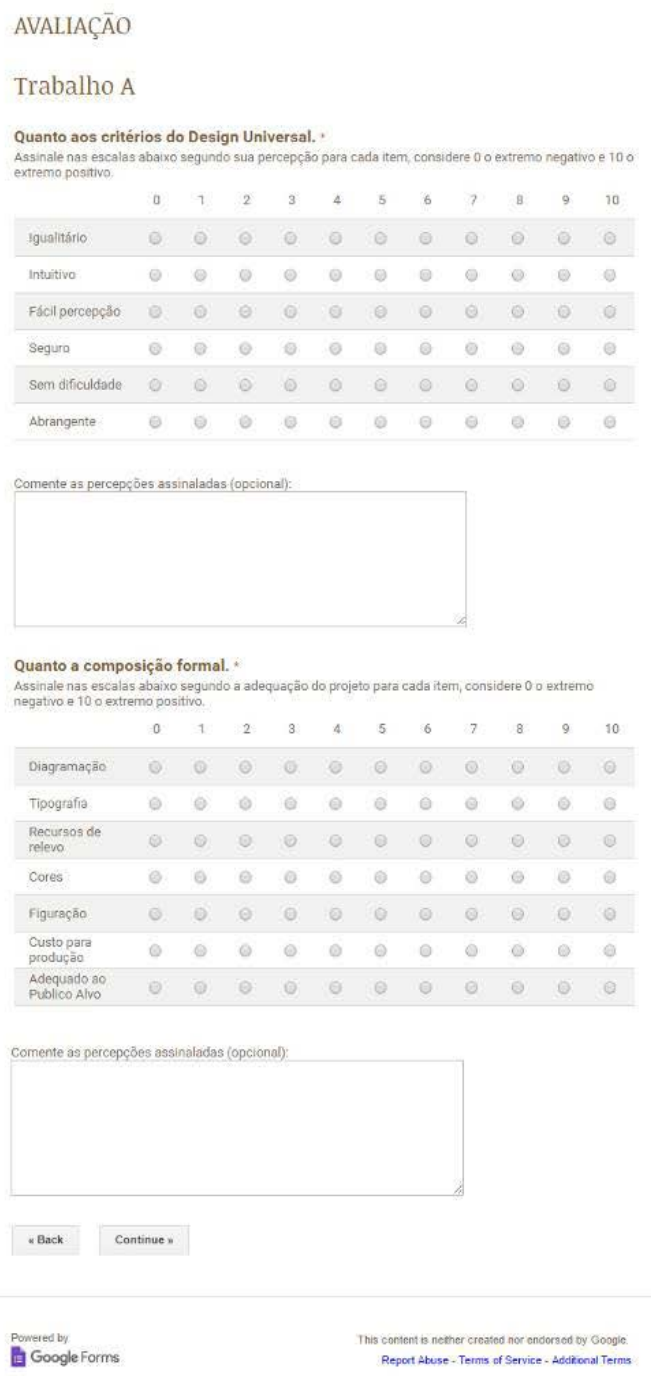

Figura 7 - Protocolo digital elaborado no Google Form.

Fonte: Elaborado pelo autor.

Este estudo foi realizado na Faculdade de Arquitetura, Artes e Comunicação da Unesp de Bauru, onde os especialistas, recebiam as páginas de cartilhas que deveriam ser avaliadas uma a uma. Estes realizavam a avaliação por meio da escala proposta e em seguida podiam acrescentar algum comentário, caso desejassem.

Os dados coletados foram organizados em planilhas, realizou-se uma análise estatística descritiva, obtendo-se o valor médio e desvio padrão para cada critério. 


\section{RESULTADOS E DISCUSSÕES}

Os resultados demonstram que quanto ao critério Igualitário foram melhor avaliadas as cartilhas A e D (figura 8), ambas com bom contraste dos elementos com 0 fundo e poucos elementos na composição do leiaute. Destacando-se a cartilha $D, a$ qual foi considerada uma das mais igualitárias provavelmente por não possuir elementos em braile visíveis. E assim, de forma contrária, pode se observar que a cartilha B foi considerada a menos igualitária, o que faz sentido, pois os elementos do braile neste leiaute estão em maior destaque por conta das estruturas das linhas e colunas aparentes. Isto diferenciou esta página das demais cartilhas avaliadas, tendo sido avaliada como pouco igualitária.

Médias - Design Universal

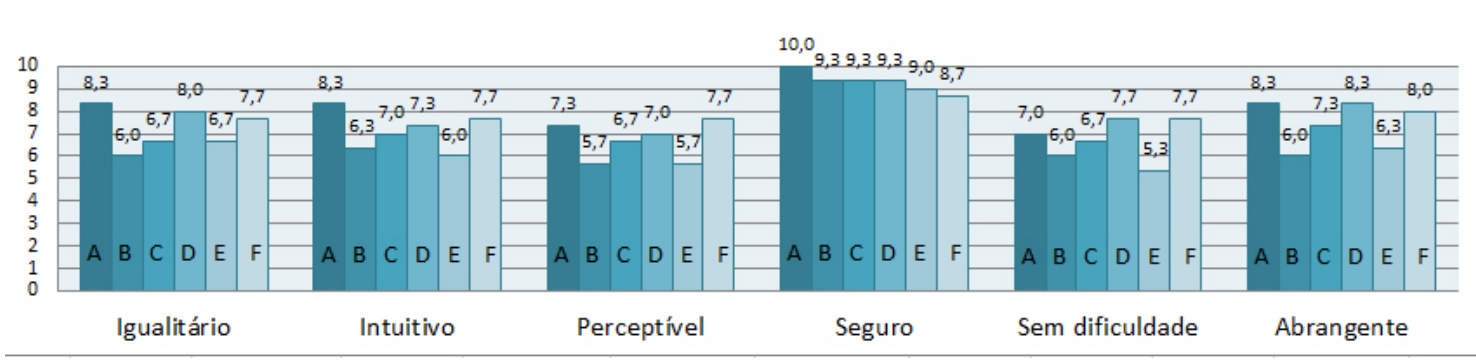

Figura 8 - Protocolo digital elaborado no Google Form.

Fonte: Elaborado pelo autor.

Para o critério Intuitividade foram melhor avaliadas as cartilhas A, D e F (figura 8), que apresentam leiautes simplificados e alto contraste entre os elementos e a cor de fundo. $E$ foi considerada a menos intuitiva a cartilha $E$, o que provavelmente ocorreu porque esta possui uma proposta de tarefa diferente das demais e que pode não ser facilmente compreendida sem um enunciado.

Para o critério fácil de perceber destacam-se como melhor avaliadas as cartilhas F, A e D (figura 8), especificamente nesta ordem, que são aquelas sem elementos de fundo e com maiores contrastes em elementos e fundo.

O critério seguro gerou dúvidas nos especialistas durante a coleta, pois acreditavam não se aplicar a este tipo de produto. No entanto, mesmo este critério apresenta uma avaliação coerente, afinal, foram percebidas como inseguras as cartilhas E e $\mathrm{F}$ (figura 8). Estes leiautes possuem elementos sobressalientes á página: na primeira, adesivos de bolinha e, na segunda, a hélice de papel presa por um metal.

As cartilhas D e F (figura 8) foram avaliadas como aquelas que não apresentam dificuldades, ao que se observa que ambas possuem poucos elementos, com pouca variação de cor e possuem fundo branco.

Para este tipo de trabalho o critério abrangência trata das questões de fácil alcance dos recursos disponíveis a todos, ficando em destaque as cartilhas A e D (figura 8), que foram também bem avaliadas nos demais critérios.

Da mesma forma, para os critérios relacionados à composição, quanto ao quesito Diagramação os melhores leiautes avaliados são os das páginas de cartilha $\mathrm{A} e$ D (figura 9). E o pior avaliado quanto a diagramação foi $E$, o que se deu provavelmente pelo excesso de elementos. 


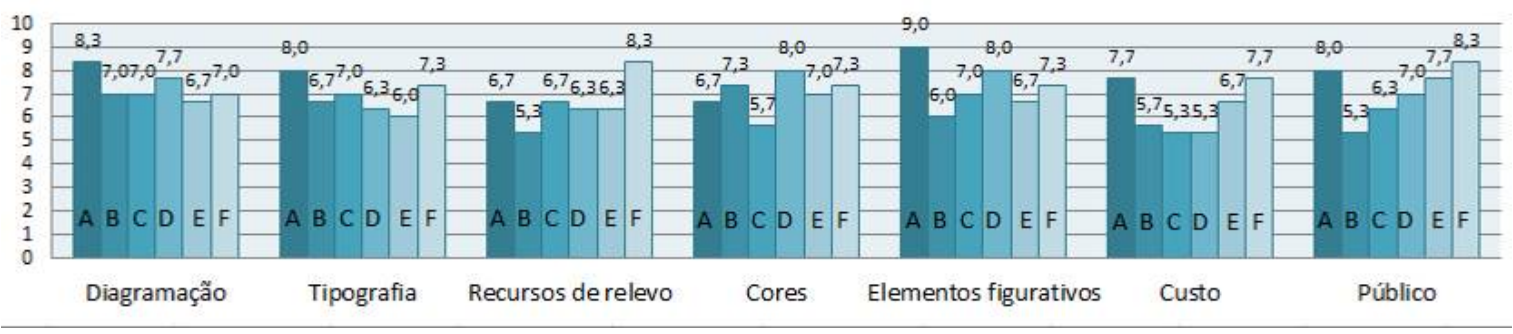

Figura 9 - Protocolo digital elaborado no Google Form.

Fonte: Elaborado pelo autor.

Quanto ao critério tipografia foram melhor avaliadas as páginas de cartilha $\mathrm{A}$ e E (figura 9), respectivamente. Na cartilha A ocorre variação de tipografias de diferentes famílias (com e sem serifa), mas que são bastante simples e estão separadas pelo elemento figurativo central. $E$ na cartilha $E$, diferentemente, utiliza-se apenas uma tipografia, que é entre todas as utilizadas nos demais projetos a mais lúdica, sendo uma tipografia do tipo fantasia.

Para os recursos de relevo destaca-se a avaliação dada a cartilha $F$ (figura 9), que foi a única que utilizou um recurso que foi além do relevo no elemento figurativo, pois permitiu interação de fato. E no extremo oposto, os elementos de relevo da cartilha B foram avaliados de forma negativa, muito provavelmente por possuírem figuras muito complexas de serem percebidas por meio apenas de linhas de contorno, como o circo ou o carro por exemplo, que possuem muitos e pequenos detalhes.

Para o critério Cor destacou-se positivamente a cartilha $D$ (figura 9), que possui fundo branco e azul escuro nos elementos principais, e negativamente a cartilha $C, 0$ que pode ter ocorrido devido ao fundo estampado com a mesma cor das letras e dos elementos figurativos. Isto pode ter permitido a sensação de pouco contraste.

Nos elementos figurativos, nota-se que a cartilha B (figura 9), que é aquela que possui maior número de elementos foi a pior avaliada, o que permite refletir que para a avaliação deste elemento não se tratou da quantidade, mas da qualidade e simplicidade dos elementos. Destacando-se neste contexto, de forma positiva, a cartilha A.

Para o critério custo de produção acredita-se que os valores atribuídos pelos especialistas não avaliou quanto a melhores (próximos de 10) ou piores (próximos de 0) custos, mas quanto a maiores (próximos de 10) e menores (próximos de 0) custos. Isto nota-se pios os três projetos com maiores médias, cartilhas A, F e E (figura 9), são aqueles que muito provavelmente seriam mais caros de produzir por possuírem elementos sobressalientes ou necessitarem de impressão em papel diferenciado - no caso de $F$, papel adesivo, por exemplo. $E$ de forma contrária, as páginas de cartilha $B, C$ e $D$, seriam as de melhor custo, pois além da impressão só exigiram os relevos necessários para leitura do braile, exigindo assim menores investimentos.

E por fim, quanto a avaliação do critério adequação ao público, destacam-se com melhor avaliação $F$ e A (figura 9), certamente as páginas mais lúdicas por possuírem elementos sobressalientes. $E$ destaca-se negativamente a cartilha $B$, provavelmente por ser aquela que focou mais o projeto nos deficientes visuais, 
deixando aparente até mesmo a grade demonstrando as linhas de grade que formam as letras em braile.

\section{CONCLUSÃO}

O presente estudo traz uma reflexão bastante relevante, que é a importância da inserção de temas que tratem de Inclusão no processo de aprendizagem de Design. $\mathrm{E}$, mesmo se tratando de um trabalho com foco bastante dirigido aos deficientes visuais, além de gerar conhecimento acerca das necessidades especiais relacionadas a esta deficiência, também permite ganhar consciência da importância de projetos que procurem de fato ser universais.

E neste sentido, acredita-se que o objetivo desse projeto, enquanto atividade didática, foi cumprido. Afinal, durante o processo de desenvolvimento destes projetos muitos alunos relataram se sentir "presos" por ter que atender a tantos requisitos, como alta legibilidade e contrate para crianças com baixa visão, por exemplo. Além disso, muitos deles entregaram o trabalho reconhecendo que não atingiram uma proposta de fato universal, pois começaram a pensar que este projeto também deveria incluir crianças daltônicas, dislexas e ainda crianças que precisariam ser alfabetizadas na linguagem surdo-mudo.

No que diz respeito à avaliação dos profissionais e aos princípios do Design Universal, nota-se que todas as propostas geraram médias acima de cinco, com destaque para as propostas de cartilha A e F. O que permite afirmar que, para os especialistas, os elementos de relevo que extrapolam a estrutura da folha permitem melhor interação e, portanto melhor inclusão.

Além disso, pode-se dizer que, embora os critérios do Design Universal utilizados aqui são geralmente relacionados a avaliação de produtos tridimensionais, esta avaliação mostrou-se bastante coerente e eficaz. Isto se evidencia na avaliação da cartilha $B$, que claramente possuía grande foco na criança com deficiência, chegando até mesmo a deixar de lado a criança com visão ao expor a grade de estrutura das letras em braile. Ao que pode-se dizer não se tratar de um projeto inclusivo, ou seja, que incluiria o deficiente visual; mas sim um projeto exclusivo, ou seja, feito apenas para o deficiente visual.

Quanto aos critérios utilizados para avaliação do projeto das páginas das cartilhas pelos especialistas, pode-se dizer que também gerou reflexões relevantes. Como quanto às cores, onde se considerou que as páginas com menos variação de cores e com fundo branco permitem um melhor contraste. Ou ainda, quando permitiu refletir que elementos figurativos simplificados são mais indicados para projetos dessa natureza.

Com ressalva para o critério Custo, cuja interpretação da avaliação ocorreu de forma contraria, onde os projetos mais caros receberam avaliação melhore os mais baratos piores, quando deveria ser o contrário.

Contudo, experiências didáticas e até mesmo a avaliação de produtos ditos inclusivos devem ser realizados de forma ampla, a fim de conhecer melhor as possibilidade de aplicação de princípios que na teoria estão muito bem estabelecidos, mas que ainda representam um desafio para o ato de projetar do designer.

Além disso, estudos dessa natureza deveriam ser ampliados buscando conhecer a aplicação para outras necessidades especiais, como as citadas aqui anteriormente (daltonismo, dislexia, por exemplo) e outras; ou ainda, para todas ao 
mesmo tempo, buscando a caracterização de um projeto realmente universal. Ao que se destaca a necessidade desses estudos não apenas como experiência didática, mas com a finalidade de gerar parâmetros de fato para o desenvolvimento de material didático de baixo custo e acessível a toda rede de ensino.

\section{REFERÊNCIAS}

ALVARENGA, F. Uma abordagem metodológica para o projeto de produtos inclusivos. Campinas: UNICAMP, Faculdade de Engenharia Mecânica, 2006.

BRUNO, M. M. G. Deficiência visual: reflexão sobre a prática pedagógica. São Paulo: Laramara, 1997.

ESTATUTO DA CRIANÇA E DO ADOLESCENTE (1990). Estatuto da criança e do adolescente: Lei n. 8.069, de 13 de julho de 1990, Lei n. 8.242, de 12 de outubro de 1991. - 3. ed. - Brasília : Câmara dos Deputados, Coordenação de Publicações, 2001. $92 \mathrm{p}$.

GASPARETT O, M. E. R. F. et al. Inclusão do indivíduo com baixa visão/cego, onde estamos e para onde vamos. I n: KARA-JOSÉ, N.; RODRIGUES, M. L. V. Saúde ocular e prevenção da cegueira. Rio de Janeiro: Cultura Médica, 2009. p. 189-196.

INEP. Resumo técnico - Censo Escolar 2010. Disponível na internet por <http://download.inep.gov.br/educacao_basica/censo_escolar/resumos_tecnicos/div ulgacao_censo2010_revisao_04022011.pdf>. Acesso em 10 de mai. de 2016.

Lopes, M. C. B. et al. Avaliação e tratamento fisioterapêutico das alterações motoras presentes em crianças deficientes visuais. Revista Brasileira de Oftalmologia, Rio de Janeiro, v. 63, n. 3., 2014, p. 155-161.

MAIA, F., FREITAS, S. Tecnologia Assistiva e Design - Conceitos e aplicações. In: Congresso Internacional de pesquisa em Design, 5., 2009, Bauru. Anais do 5o CIPED Congresso Internacional de pesquisa em Design. Bauru - São Paulo, 2009.

MENDES, E.G. A radicalização do debate sobre inclusão escolar no Brasil. Revista Brasileira de Educação, v. 11, n. 33 set./dez, 2006.

ORGANIZAÇÃO MUNDIAL DE SAÚDE (OMS). CID- 10. Classificação estatística internacional de doenças e problemas relacionados à saúde. 9. ed. rev. São Paulo: EDUSP, 2003.

RADABAUGH, M. P. Study on the Financing of Assistive Technology Devices of Services for Individuals with Disabilities - A report to the president and the congress of the United State, National Council on Disability, Março 1993. Disponível na internet por <http://www.ccclivecaption.com> Acesso em 05 de mai. 2016.

RIBEIRO, M. et al. O Design Universal como abordagem ergonômica na concepção de produtos. In: Congresso de gestão de desenvolvimento de produto, 3., 2001, Santa Catarina. Anais do 3ㅇ Congresso de gestão de desenvolvimento de produto. Santa Catarina, 2001.

SANTANA, C. L. et al., Inclusão escolar: a utilização da tecnologia assistiva na educação regular. In: Simpósio Educaçãoe Comunicação: info-inclusão e possibilidades de 
ensinar e aprender, 3. 2012, Sergipe. Anais do 3o Simpósio Educaçãoe Comunicação. Sergipe, 2012.

SANTOS, A. C. F. et al. Reflexões sobre a tecnologia assistiva no atendimento ao deficiente físico. Trabalho apresentado como requisito parcial para a aprovação em disciplina, Pós-graduação em Ed. Especial na Perspectiva da Inclusão, Faculdades integradas Ipiranga, 2014.

SOARES, A. L. et al. Investigando a tecnologia assistiva para deficientes visuais através de uma experiência de estágio supervisionado. In: Seminário Nacional de Inclusão Digital, 2., 2013, Anais do 2ㅇ Seminário Nacional de Inclusão Digital. São Paulo, 2012. WEST, S.; SOMMER, A. Prevention of blindness and priorities for the future. Bulletin of the World Health Organization, New York, v. 79, n. 3, p. 244-248, 2001. 